\title{
INOVAÇÕES SOBRE SISTEMAS DE EMBALAGENS PARA ALIMENTOS PROCESSADOS TERMICAMENTE
}

ALLINEARTIGIANI LIMATRIBST* JOSÉ DE ASSIS FONSECA FARIA**

\begin{abstract}
Esta revisão de literatura teve como objetivo avaliar os diferentes sistemas de embalagem disponíveis para alimentos termicamente processados e como as embalagens afetam o tipo de processo utilizado e a qualidade final do produto obtido. Foram abordados os principais processos térmicos utilizados e os seus requerimentos em termos de resistência (mecânica e térmica) da embalagem, além das vantagens e limitações dos principais materiais utilizados. Também foram tratados os desenvolvimentos recentes e importantes para superar parcialmente as limitações de cada tipo de material e reduzir os custos envolvidos, além das propriedades de barreira exigidas para que o alimento não sofra alterações, especialmente de ordem físico-química por oxidação, umidade e migração de materiais da embalagem, durante o seu armazenamento. Concluiu-se que existem várias opções de embalagens para alimentos termicamente tratados e que, enquanto embalagens tradicionais passam por constantes pesquisas para se manterem competitivas, as de plástico ou flexíveis são muito estudadas visando o desenvolvimento de sistemas compatíveis com o processamento térmico e baixo custo.
\end{abstract}

PALAVRAS-CHAVE: TRATAMENTO TÉRMICO; ENCHIMENTO A QUENTE; RESISTÊNCIA TÉRMICA DE EMBALAGENS; VIDROS; LATAS.

** Mestre em Engenharia de Alimentos, Departamento de Engenharia de Alimentos, Faculdade de Engenharia de Alimentos, Universidade Estadual de Campinas (UNICAMP), Campinas, SP, Brasil (email: alline.lima.tribst@gmail.com) .

** Professor Titular, Faculdade de Engenharia de Alimentos, UNICAMP, Campinas, SP, Brasil (e-mail: assis@fea.unicamp.br). 


\section{INTRODUÇÃO}

Os alimentos são facilmente contaminados por microrganismos que consomem seus nutrientes e produzem metabólitos como ácidos, alcoóis (JACXSENS et al., 2003) e enzimas como proteases e lipases (HOCKING, 2006). O desenvolvimento de microrganismos, seja pelo seu crescimento aparente ou devido aos efeitos de seus metabólitos, resulta na rápida deterioração dos alimentos reduzindo sua vida útil. Exemplo disso foi demonstrado por HAYNES (1996 citado por PINHO, 2007) que observou contagem inicial de $10^{3}$ a $10^{4} \mathrm{UFC} / \mathrm{mL}$ para leite recém ordenhado em boas condições de limpeza. Resultados obtidos por AVERY, HUDSON e PHILLIPS (1996) evidenciaram que em 48 horas alguns microrganismos mantidos a $13^{\circ} \mathrm{C}$, como Pseudomonas e Listeria, podem apresentar aumento na população de 11,4 ciclos logarítmicos, tornando o produto impróprio para o consumo.

A extensão da estabilidade dos alimentos pode ser obtida mediante aplicação de processos que reduzam substancialmente a sua contaminação inicial, como o tratamento térmico (MAROULIS e SARAVACOS, 2003). Segundo GHANI et al. (1999) esse é um dos métodos mais efetivos para a conservação de alimentos, especialmente quando realizado com o produto já embalado. A extensão da vida útil do alimento promovida por esse processo é essencial para sua comercialização (BOWN, 2003).

Os tipos de processo térmicos mais comuns são o branqueamento, a pasteurização e a esterilização. Enquanto o branqueamento visa à inativação de enzimas do próprio alimento, os processos de pasteurização e esterilização são voltados para a inativação de microrganismos (MAROULIS e SARAVACOS, 2003).

A aplicação de tratamento térmico eficiente não garante a boa estabilidade do produto, visto que quando não acompanhado de processo de envase adequado pode ocorrer a recontaminação do alimento após o processamento (VIEIRA, 2007). Dentre as funções da embalagem destaca-se a proteção do alimento contra materiais externos (como microrganismos, insetos, vermes e materiais estranhos) e outros agentes que podem deteriorar o alimento como luz e oxigênio. Além disso, a embalagem deve apresentar propriedades mecânicas e térmicas que garantam a estabilidade do alimento durante o processamento (BOARD, STEELE e KELLY, 2001).

A disponibilidade de materiais de embalagem para alimentos processados termicamente aumentou pelo desenvolvimento de tecnologias envolvendo novos polímeros e embalagens flexíveis convertidas e, também, de novos processos que passaram a permitir o tratamento térmico em embalagens flexíveis (SARANTÓPOULOS e JESUS JR, 2007). A presente revisão teve por objetivo avaliar os diferentes sistemas de embalagem disponíveis para alimentos termicamente processados, como as embalagens afetam o tipo de processo utilizado e também a qualidade final do produto obtido.

\section{TRATAMENTO TÉRMICO}

O tratamento térmico, um dos métodos mais utilizados para a conservação de alimentos (GHANI et al., 2001), constitui processo seguro, barato e eficiente na obtenção de produto estável.

A escolha do tratamento térmico deve ocorrer em função da resistência térmica do microrganismo alvo, sua contagem inicial no alimento (STUMBO, 1973) e a probabilidade de unidades não estéreis (PUNE) consideradas seguras para o processo (PFLUG, 1999). Esses fatores, muitas vezes, resultam na necessidade de aplicação de processo térmico severo, com altas temperaturas e longos tempos de retenção. Todavia, esses processos térmicos provocam alterações indesejáveis nas características sensoriais de cor (DAMASCENO et al., 2008; CHUTINTRASRI e NOOMHORM, 2007), do aroma/sabor (SHIMODA et al., 2003) e da textura (STUMBO, 1973) dos alimentos. Além das perdas sensoriais, também podem ocorrer alterações nutricionais devido à degradação de vitaminas (VÁSQUEZ-CAICEDO et al., 2007; RICKMAN, BARRETT e BRUHN, 2007). A pasteurização e a esterilização comercial constituem os dois principais tipos de processos térmicos aplicados pela indústria de alimentos visando a conservação dos seus produtos. 
A pasteurização visa inativar microrganismos patogênicos (MAROULIS e SARAVACOS, 2003) e enzimas que podem deteriorar o produto durante a estocagem, causando, por exemplo, escurecimento e separação de fases (FELLOWS, 2000). Esse processo é largamente aplicado para a conservação de sucos, leites, bebidas fermentadas, palmito e outras conservas e sua utilização implica na necessidade de associação com outro método de conservação, como a refrigeração (POTTER e HOTCHIKISS, 1995). A extensão da vida útil será de apenas alguns dias para alimentos pouco ácidos, enquanto alimentos ácidos podem ter extensão da estabilidade por meses (FELLOWS, 2000). A pasteurização pode ser realizada em trocadores de calor para alimentos fluidos ou particulados, com posterior embalagem (FELLOWS, 2000), em túneis de pasteurização ou banhos de aquecimento para alimentos previamente embalados, principalmente para alimentos sólidos (FELLOWS, 2000; BOWN, 2003).

A esterilização comercial constitui processo capaz de inativar todas as enzimas (FELLOWS, 2000) e os micro-organismos (STUMBO, 1973) aptos a deteriorar um alimento durante seu armazenamento à temperatura ambiente. Trata-se de método de conservação bastante aplicado para alimentos de baixa acidez, como leite, milho, ervilha e outros legumes que podem estar contaminados com esporos de Clostridium botulinum, os quais representam risco potencial à segurança do produto e precisam ser inativados. No processo de esterilização comercial são usadas temperaturas de $121^{\circ} \mathrm{C}$ por minutos ou horas (para conservas) e até $140^{\circ} \mathrm{C}$ por segundos (para leite). O processo pode ser realizado em alimentos embalados ou não. No caso de alimentos embalados, o tratamento térmico ocorre em autoclaves pelo processo contínuo ou em bateladas (BOWN, 2003). Para alimentos líquidos ou particulados não acondicionados, a esterilização ocorre de forma contínua em equipamentos de tratamento por ultra high temperature (UHT), mediante contato direto ou indireto com o vapor (MAROULIS e SARAVACOS, 2003). Após o tratamento térmico e resfriamento, esses alimentos precisam ser embalados em condições assépticas para garantir sua estabilidade.

\subsection{ACONDICIONAMENTO DEALIMENTOS TERMICAMENTE INDUSTRIALIZADOS}

Quando o alimento é tratado termicamente na embalagem, caso dos sistemas de autoclaves ou túnel de pasteurização, o enchimento ocorre previamente ao processo térmico e a embalagem utilizada deve ser resistente à temperatura do processo para não sofrer deformações que comprometam a sua hermeticidade. Além disso, deve apresentar resistência mecânica suficiente para tolerar impactos, especialmente nos processos contínuos em que a embalagem se movimenta, e também durante a estocagem e distribuição (BOARD, 2001).

Para alimentos tratados termicamente na embalagem, além da resistência térmica e mecânica, deve-se considerar as suas dimensões. Todo o processo térmico é estabelecido para o ponto frio da embalagem, ou seja, o ponto de aquecimento mais lento. Caso a embalagem seja muito grande ocorre aumento do binômio tempo/temperatura requeridos pelo tratamento (FELLOWS, 2000), que resultará em perda de qualidade do produto.

Para alimentos tratados termicamente antes de serem acondicionados, o processo de embalagem pode ser feito a quente ou a frio. No caso de processo a frio, o ambiente deve ser estéril para a impedir a recontaminação do alimento. Quando isto não é possível, torna-se necessário o uso de aditivos no produto para garantir que o mesmo não sofrerá recontaminação. $O$ processo de enchimento a quente (hot fill) é destinado para alimentos líquidos e ácidos, como sucos de frutas (ÁVILAe SILVA, 1999), sendo recomendável para alimentos com pH igual ou menor do que 4 (McLELLAN e PADILLA-ZAKOUR, 2005). Esses alimentos são tratados nas condições de tempo/temperatura requeridas para inativação microbiológica e, em seguida, acondicionados. A temperatura de enchimento adequada varia entre $88-95^{\circ} \mathrm{C}$, a qual deve-ser mantida por 3 minutos antes do resfriamento de forma a garantir a adequada esterilização da embalagem (McLELLAN e PADILLA-ZAKOUR, 2005). Tais processos exigem o resfriamento posterior em tanques ou com jatos de água fria (ÁVILA e SILVA, 1999). 
Para alimentos processados termicamente e posteriormente resfriados é necessário (para garantir a efetividade do processo) que a etapa da embalagem seja realizada em ambiente asséptico. As principais vantagens do sistema asséptico com relação ao hot fill incluem a possiblidade de aplicação a todos os tipos de alimentos, o uso de materiais de embalagens mais baratos, pois não precisam apresentar resistência térmica (McLELLAN e PADILLA-ZAKOUR, 2005), e resulta em produto com melhor qualidade, devido ao menor tempo de aquecimento do alimento.

No processo asséptico, a etapa de embalagem de alimentos ocorre em ambiente "limpo" - isento de microrganismos - com o alimento e a embalagem previamente esterilizados (ANSARI e DATTA, 2003). O processo de esterilização da embalagem pode ser feito por calor, peróxido de hidrogênio, irradiação, luz infravermelha ou pela combinação de mais de um desses métodos. A escolha baseia-se na atividade microbicida, compatibilidade com o material de embalagem, facilidade na eliminação dos resíduos, capacidade de corrosão do material de embalagem e custo do processo de esterilização (ANSARI e DATTA, 2003). O sistema asséptico apresenta alto custo pela exigência de ambiente limpo e a utilização de sistema com pressão positiva de ar estéril (SANDEEP, SIMUNOVIC e SWARTZEL, 2004). O processo contínuo exige também o uso de tanque pulmão estéril, que onera ainda mais o custo da planta (SANDEEP, SIMUNOVIC e SWARTZEL, 2004). Por esse motivo, às vezes as empresas optam por outro sistema de embalagem, apesar da qualidade garantida de produtos assépticos.

A opção de envase a frio para alimentos sem sistema asséptico baseia-se na utilização de conservantes para manutenção da estabilidade microbiológica do produto, sendo ainda necessária, em alguns casos, a manutenção do alimento sob refrigeração (MCLELLAN e PADILLA-ZAKOUR, 2005). Trata-se de técnica utilizada para alimentos ácidos e os principais conservantes utilizados são os ácidos sórbico e benzóico e seus sais, cuja principal ação é a inibição de bolores e leveduras (CHIPLEY, 2005), incluindo os bolores termorresistentes e minimizar o risco de produção de micotoxinas. Segundo WALKER e PHILLIPS (2007), os benzoatos e sorbatos também podem promover a inativação de microrganismos termorresistentes como o Alicyclobacillus acidoterrestris e o Propionibacterium cyclohaxanicum. Isso é extremamente importante quando se objetiva minimizar as condições de tempo e temperatura utilizadas no tratamento térmico, visando a manutenção da qualidade do produto.

\section{OPÇÕES DE MATERIAIS DE EMBALAGEM}

A necessidade do homem de embalar seus alimentos surgiu com o desenvolvimento das relações de troca utilizando alimentos como moeda. As primeiras embalagens eram feitas de materiais extraídos da natureza, como madeira, pedras e pele animal. O desenvolvimento dos processos para conservação de alimentos passou a exigir novos materiais para embalagem, que fossem compatíveis com a extensão de vida útil obtida pelos métodos de conservação (CUTTER, 2002).

O primeiro relato de conservação de alimentos mediante tratamento térmico data de 1809 , quando Nicolas Appert preservou alimentos embalados em potes de vidro pelo cozimento dos mesmos em banho de água quente. Em 1810, o surgimento das embalagens metálicas alavancou a industrialização de alimentos processados termicamente e, em 1840, Pasteur observou a esterilização de microrganismos quando submetidos às condições de aquecimento com vapor (CUTTER, 2002). Somente em 1910 foi produzida comercialmente a primeira lata de alumínio e em 1929 foi utilizada, pela primeira vez, a injeção de vapor para produção de vácuo em latas. Em 1950, a necessidade de conservação prolongada levou ao desenvolvimento de latas com recobrimento (verniz). Entre as décadas de 1960 e 1970 ocorreu a explosão das embalagens flexíveis e, na década de 1980 foi desenvolvido o sistema de envase asséptico que modificou os conceitos de alimentos tratados termicamente (CUTTER, 2002). No entanto, as primeiras embalagens cartonadas foram desenvolvidas em torno da década de 1950 (TETRAPAK, 2008). 
Estão disponíveis no mercado de embalagens para alimentos termicamente tratados, desde as tradicionais embalagens de vidro (que passaram por poucas alterações nos últimos 200 anos) até as embalagens plásticas e aquelas com camadas de diferentes materiais em sua composição, como os laminados cartonados da Tetra $\mathrm{Pak}{ }^{\circledR}$. A perspectiva é que esse ramo de inovações em materiais de embalagem continue se desenvolvendo de forma a atender a demanda crescente dos consumidores (BOARD, STEELE e KELLY, 2001).

\subsection{VIDRO}

O vidro, primeiro material de embalagem utilizado para alimentos tratados termicamente (CUTTER, 2002), apresenta características como maior inerticidade (quando comparada com outros materiais) e excelente barreira aos gases e aromas. Entretanto, o seu custo, peso e fragilidade (CUTTER, 2002) fazem com que o material perca cada vez mais espaço no mercado para as embalagens plásticas. A embalagem de vidro pode apresentar problemas de hermeticidade, visto que são normalmente fechadas com tampas metálicas contendo anel de vedação (BOARD, STEELE e KELLY, 2001) que, se não dimensionadas corretamente, podem permitir a entrada de água do processo (em alimentos tratados na embalagem) causando recontaminação do produto. Isto é favorecido no tratamento de esterilização, cuja diferença de pressão existente entre o interior e o exterior da embalagem deve ser bem controlada. A embalagem de vidro pode quebrar quando submetida à rápida mudança de temperatura, o que depende do tamanho, formato, uniformidade e espessura do vidro (BOARD, STEELE e KELLY, 2001). Geralmente, a diferença de temperatura de $30^{\circ} \mathrm{C}$ é suficiente para promover a quebra de embalagens comuns. Quando se deseja fazer o tratamento térmico de produtos embalados em vidro deve-se considerar o gradiente de temperatura do meio de aquecimento, não sendo possível a utilização de temperaturas elevadas desde o início do processo (BOARD, STEELE e KELLY, 2001).

Segundo JAIME e ORTIZ (2001), o futuro das embalagens de vidro para alimentos e bebidas depende da habilidade das indústrias vidreiras em desenvolver recipientes mais leves, mais resistentes e com custo mais competitivo. Por esse motivo, o processo de produção de embalagens de vidro tem mudado, especialmente para garrafas de bebidas (JAIME e ORTIZ, 2001). Está sendo realizada a substituição do tradicional processo de sopro-sopro pelo processo de prensagem-sopro para embalagens de boca estreita, o que resulta em melhor distribuição da massa vítrea, formando paredes com espessuras mais homogêneas (DANTAS e JAIME, 2003). Esse sistema de produção de garrafas permitiu a redução de peso das embalagens em até $40 \%$ e o aumento das resistências mecânicas e ao choque térmico. Nesse processo, forma-se a garrafa por prensagem da massa vítrea pela ação de pistão metálico (JAIME, 1997). Isso garante espessura homogênea e minimiza falhas no vidro e a consequente perda da resistência térmica (DANTAS e JAIME, 2003). Outra forma de reduzir a espessura de garrafas de vidro envolve a aplicação de revestimento de poliuretano externo, que possibilita a redução da espessura das garrafas em até $40 \%$ sem perda de propriedades mecânicas (ORTIZ, 1996). Esse revestimento, entretanto, não melhora as propriedades térmicas do vidro, pois se trata de polímero que pode perder a rigidez durante o processo térmico. JAIME (1997) também observou que a redução de peso das garrafas pode ser efetiva quando utilizadas diferentes composições de vidro na confecção da embalagem.

Importante inovação para garrafas de vidro foi seu tratamento superficial a quente e a frio. $\mathrm{O}$ tratamento a quente ocorre a $600^{\circ} \mathrm{C}$ pela aspersão de tetracloreto de estanho na parte externa da garrafa, formando óxido de estanho que preenche possíveis microfissuras do vidro e aumenta sua resistência e dureza (JAIME e ORTIZ, 2001; ORTIZ, 1996). O tratamento a frio é feito com polietilenoglicol, ácido oleico ou esteárico para reduzir o coeficiente de atrito, minimizando o efeito do choque mecânico entre garrafas em linhas de produção (JAIME e ORTIZ, 2001; ORTIZ, 1996).

Apesar das embalagens de vidro terem sofrido alterações visando, principalmente, a redução de peso do material com a consequente diminuição de custo, poucas dessas alterações resultaram em maior resistência ao processo térmico. Assim sendo, quando se usa vidro para envase de alimentos 
que serão posteriormente autoclavados, é preciso considerar o desenho da autoclave que deve apresentar zonas de aquecimento controladas para evitar choque térmico a temperaturas muito altas. Também exige sistema de contrapressão eficiente, visando manter pressão igual dentro e fora da embalagem para minimizar os riscos da entrada de água da autoclave. Para produtos pasteurizados, nos quais todo o tratamento térmico ocorre à pressão atmosférica, recomenda-se cautela com as temperaturas utilizadas no processo para evitar choque térmico e a consequente quebra da embalagem.

\subsection{LATAS}

As latas destinam-se majoritariamente para alimentos tratados termicamente na embalagem (CUTTER, 2002), dada suas propriedades de resistência, velocidade de fabricação, facilidade de enchimento e recravação, além da habilidade para suportar altas temperaturas e pressões (CUTTER, 2002). As embalagens metálicas são compostas de folhas de flandres, folhas cromadas ou de alumínio, geralmente envernizadas. Sua resistência apresenta relação direta com seu diâmetro, sendo maior quanto menor for o tamanho da embalagem (BOARD, STEELE e KELLY, 2001).

Quanto à resistência mecânica, as latas toleram bem o processo de autoclavagem e não requerem o uso de contrapressão para manutenção de sua integridade (BOARD, STEELE e KELLY, 2001). A hermeticidade da lata depende da qualidade de sua recravação, processo no qual a tampa e/ou o fundo da lata é recravado ao seu corpo e da não ocorrência de impactos durante a vida útil do produto. Os amassamentos, especialmente na recravação, podem resultar na formação de micro furos com possível contaminação do alimento após o processamento (BOARD, STEELE e KELLY, 2001).

As modificações das embalagens metálicas foram necessárias para mantê-las no mercado, visando prioritariamente a redução do custo (PRIA, 2000). As principais medidas para a redução de peso dessas embalagens foram: 1) redução do diâmetro da tampa de 65 para $52 \mathrm{~mm}$, com consequente diminuição de consumo de material de embalagem, além de melhoria no empilhamento; 2) redução da espessura das latas, devido ao processo de embossing/debossing que representa a formação de relevos na lata e que possibilita a utilização de espessuras mais finas sem comprometer a sua resistência e 3) substituição dos vernizes comuns por vernizes poliméricos, que auxiliam na obtenção de lata com menor espessura (PRIA, 2000).

Melhorias na obtenção da embalagem, como sua confecção em novos formatos mais atraentes, foram viabilizados pela expansão do corpo da lata (GONZALEZ e ZEPKA, 2004) e, também pelos novos tipos de aberturas, especialmente para latas de bebidas (PRIA, 2000).

As alterações na estrutura da lata, visando a redução de peso e manutenção da resistência mecânica, foram estudas por WANG (2001) considerando os três principais fatores de estrutura da lata: a sua carga axial (carga de empilhamento), sua conformação para evitar o abaulamento (em condições de alta pressão na lata) e suas características de parede (sem colapso da mesma em condições de alta pressão no meio externo). Observou que o uso de relevos na lata auxilia a manutenção das características de parede e evita o abaulamento, mas resulta em pior desempenho frente à carga axial (especialmente para relevos profundos), sendo necessária a otimização da profundidade e distribuição dos relevos, visando minimizar a espessura da parede e, consequentemente, a quantidade de material requerida para a embalagem.

A TEIJIN LIMITED (1997), detentora da patente US 005618621A, desenvolveu filme biorietado axialmente de poliéster combinado, que tem ponto de fusão acima de $180^{\circ} \mathrm{C}$ para recobrimento de latas tratadas termicamente. Isso aumentou a resistência térmica da lata durante a autoclavagem, a resistência ao impacto, a retenção de aromas e suas propriedades anticorrosivas. Propuseram a laminação da resina sobre as placas de metal com três camadas de material, sendo as duas primeiras de polietileno tereftalato (PET) com outro poliéster e a terceira de butileno-teraftalato com poliéster. Conseguiram atingir as condições de transição vítrea e ponto de fusão necessários e obtiveram recobrimento de 6 - 75 micrometros. A mesma empresa (TEIJIN LIMITED, 1995) já havia desenvolvido 
outro recobrimento para latas utilizando polímeros de poliéster obtidos por policondensação catalisada por germanium, com ponto de fusão de $210-245^{\circ} \mathrm{C}$ e transição vítrea de $50^{\circ} \mathrm{C}$. Esse recobrimento melhorou as propriedades de moldagem do metal, permitindo a conformação de embalagens mais arrojadas e garantindo também sua resistência ao processo térmico.

A empresa TOYO SEIKAN KAISHA (2004) desenvolveu e patenteou (US 00676470B2) recobrimento para latas utilizando poliéster e polímeros de etileno em proporção de até 50:50, sendo que o polímero de etileno continha resina de ionômero contendo zinco. Essa resina pode ser moldada sobre o metal, recobrindo a superfície da lata e melhorando as propriedades de moldabilidade e também suas propriedades térmicas, tornando-a mais resistente ao tratamento. A comparação das duas proposições acima para recobrimento de latas mostra que os resultados obtidos por TOYO SEIKAN KAISHA (2004) são promissores, devido ao menor custo. A substituição dos vernizes orgânicos proposta por esses grupos facilita a aplicação e minimiza a ocorrência de pontos sem recobrimento, dificultando a ocorrência de corrosão externa durante a sua vida útil. Além disso, a resistência mecânica conferida pode resultar em redução na espessura da lata e de custo da embalagem.

O processo patenteado (US 005721020A) por KANSAI PAINT (1998) emprega a radiação ultravioleta (UV) para a cura de polímeros utilizados para recobrimento de latas. Isso melhorou o desempenho dos polímeros com relação a processabilidade da embalagem, dureza, adesividade e, especialmente quanto à aparência da lata e de sua resistência ao processo térmico. Para obtenção desses efeitos, a camada de recobrimento da lata deve conter composto com cátion polimerizável (ex. moléculas que contém um grupo epóxi), composto contendo pelo menos um anel de oxitano em sua molécula e o gerador de cátions, que libera cátions quando irradiado com luz ultravioleta.

\subsection{EMBALAGENS PLÁSTICAS}

As embalagens plásticas (flexíveis e rígidas) são produzidas a partir de polímeros orgânicos obtidos do fracionamento do petróleo (KAREL e LUND, 2003). Seu uso no mercado de embalagens tem crescido fortemente em detrimento das embalagens metálicas, de vidro e de papel. Isso pode ser atribuído à melhoria contínua dessas embalagens e ao seu baixo custo em relação aos outros materiais (GILES e BAIN, 2001). Dentre os grupos de embalagens plásticas destacam-se os poliolefícos (polietileno e polipropileno), os derivados vinílicos (polivinil álcool, polivinil acetato e polivinil cloreto), os poliésteres, os polifluorcarbonos, as poliamidas e as polinitrilas (KAREL e LUND, 2003).

As propriedades de cada polímero variam em função de sua estrutura química (KAREL e LUND, 2003). A combinação de mais de um polímero permite minimizar suas deficiências individuais, possibilitando a utilização de menores espessuras (GILES e BAIN, 2001) para constituição da embalagem (OWENS-ILLINOIS INC., 1986).

A partir do polietileno, o primeiro plástico a ser produzido, foram sendo desenvolvidas variações desse polímero (polietileno de alta densidade, polietileno de baixa densidade, polietileno linear de baixa densidade) (GARCIA, 2002). As embalagens de cloreto de polivinila (PVC) foram utilizadas para contato com alimentos até meados da década de 1990. As embalagens de polietileno tereftalato (PET), que haviam entrado no mercado de refrigerantes em 1980, conquistaram outros mercados por suas características como alta transparência e baixo peso (GILES e BAIN, 2001).

Com relação aos alimentos termicamente processados, o uso de embalagens plásticas é limitado muitas vezes por sua baixa resistência térmica. Portanto, torna-se viável para a maioria dos polímeros apenas em sistemas de embalagem a frio, como o sistema asséptico ou o sistema a frio com adição de conservantes.

A baixa resistência térmica dos materiais de embalagem ocorre pelo baixo ponto de fusão da maioria dos materiais poliméricos, o que resulta na deformação da embalagem quando submetida ao calor e muitas vezes na perda de sua hemerticidade. Essa baixa resistência térmica, atribuída à pequena rigidez mecânica, faz com que após o envase e o fechamento da embalagem com o alimento quente ocorra a contração da suas paredes (OWENS-ILLINOIS INC., 1986) pela diferença de pressão 
entre o ambiente interno e externo da embalagem (BOARD, STEELE e KELLY, 2001). O enchimento a quente de garrafas plásticas cilíndricas de baixa resistência térmica provoca afunilamento no centro da sua estrutura (colapsagem), deixando a garrafa parecida com uma ampulheta (OWENS-ILLINOIS INC, 1986). Outro problema relacionado à resistência térmica das embalagens plásticas envolve a integridade do seu sistema de fechamento, pois a fusão termoplástica que ocorre no fechamento é mais facilmente deformável pela ação do calor, especialmente quando se trata de embalagens utilizadas para alimentos submetidos ao processo de autoclavagem (BOARD, STEELE e KELLY, 2001). Apesar disso, as embalagens plásticas apresentam características importantes, como grande versatilidade de formatos e tamanhos, baixo peso e custo de material e menor gasto de energia para produção e transporte das embalagens (TUNG, BRITT e YADA, 2000). Por esse motivo, as indústrias de embalagem desenvolveram novos materiais (HNA HOLDINGS INC, US 6.063.465, 2000), a laminação (UNION CAMP CORPORATION, US 4.994.324, 1991), a coextrusão e a modificação da geometria das embalagens (OWENS-ILLINOIS INC, US 4.610.366, 1986), visando atender o mercado de alimentos termicamente processados na embalagem e sistemas de enchimento a quente.

As primeiras modificações na estrutura da embalagem foram feitas para produtos como o catchup, que necessita ser espremido para sair da embalagem sem que a mesma se deforme permanentemente. Nesse caso, a substituição da estrutura cilíndrica pela ovalada ou com painéis planos foi suficiente para a obtenção de embalagem adequada. Entretanto, essas alterações não melhoraram a resistência térmica da embalagem (OWENS-ILLINOIS INC, 1986). Na patente da OWENSILLINOIS INC (US 4.610.366, 1986), a modificação da geometria da embalagem visa garantir maior resistência ao colapso durante o enchimento a quente de garrafas. Foram inseridas na configuração da garrafa corrugações horizontais paralelas dispostas em série com paredes planas e cantos afiados, que são flexionados durante o enchimento da garrafa, permitindo que a mesma se encolha enquanto quente e depois volte à configuração original. Para tornar esse processo viável, ainda foi necessário utilizar plástico multicamadas coextrusado, contendo pelo menos uma camada de polímero estrutural que apresentasse boa resistência térmica (como EVA ou PVdC) e adesivos especiais entre as camadas que as forçassem a permanecer unidas durante o processo de enchimento.

APOLYKRAPOV e RAMALINGAM (Patente US 0129598, 2004) propôs a utilização de garrafa cilíndrica apenas na base e no topo, com o corpo poligonal contendo painéis planos que suportam radialmente as pressões geradas durante o resfriamento de produto enchido a quente sem se deformar. A HARNESS, DICKEY e PIERCE (Patente US 0039918A1, 2007) comprovou a viabilidade da produção de garrafas retangulares para enchimento a quente desde que tenham "ombros" desenhados para absorção da pressão do vácuo (acomodação das forças geradas pelo vácuo), paredes com suporte e base com configuração octogonal contendo corrugações em todo o corpo. Isso mostra que é possível a utilização de PET comum, sem alterações em sua estrutura molecular ou necessidade de laminação para a obtenção de garrafa para enchimento a quente entre 68 e $96^{\circ} \mathrm{C}$, desde que sejam realizadas as alterações sugeridas na sua geometria. Outro tipo de configuração, patenteada pela GRAHAM PACKING COMPANY (US 0125743A1, 2007), é a garrafa com corpo composto de painéis de absorção de pressão negativa (vácuo) em espirais $\left(45^{\circ}\right)$ capaz de suportar o enchimento a $82^{\circ} \mathrm{C}$ sem se deformar. Pode ser constituída de plásticos como PET, polietileno de alta ou baixa densidade, poliamida, nylon, poliésteres ou PEN, possibilitando a pasteurização do produto na embalagem.

Segundo a patente da UNION CAMP CORPORATION (US 4.994.324, 1991), a obtenção de material plástico compatível com sistema de enchimento a quente é possível, desde que seja utilizada composição mista de polímeros. A empresa produziu bags plásticos utilizando $20-50 \%$ de terpolímero de etileno, propileno, buteno, hexano ou borracha de polipropileno adicionada de $3 \%$ de anidrido maleico e $20-75 \%$ de PP. Quando comparado com as propriedades de PE e PP, esses bags apresentaram maior resistência ao enfraquecimento e ao encolhimento causados pela ação do calor, o que foi atribuído ao aumento da rigidez e força estrutural da embalagem pela combinação de polímeros.

A HNA HOLDINGS INC (patente 6.063.465, 2000) alterou a estrutura polimérica do poliéster pela adição de dietilenoglicol, isosorbide (proveniente de fontes naturais como açúcar e amido) e 
teraftaloil. A resina obtida foi extrusada, gerando pré-forma, que após soprada fornece a forma final da garrafa. Essa garrafa apresentou boa resistência ao enchimento a quente, mesmo em temperaturas superiores a $88^{\circ} \mathrm{C}$ com redução de volume máxima de $3 \%$.

A patente da EASTMAN KODAK COMPANY $(5.006 .613,1991)$ também se baseia na combinação de polímeros para produção de garrafa para enchimento a quente. Utilizaram mistura de PET e PEN (poli etileno naftalato) e um copoliéster contendo ácidos teraftálicos e naftalenodicarboxílico e etilenoglicol para obtenção de garrafas com boa transparência e alta resistência térmica, com temperatura de transição vítrea entre 85 e $111^{\circ} \mathrm{C}$.

As garrafas destinadas ao enchimento a quente também podem ser utilizadas para pasteurização do alimento embalado, o que é definido pela não ocorrência de deformação/perda de hermeticidade durante o processamento. Como exemplo, tem-se o uso de garrafas laminadas com PET e PEN, nylon ou PET e Poliamida para a pasteurização de cervejas na embalagem, sem que ocorram deformações durante o processo de pasteurização (OLIVEIRA, 1999). Essas garrafas plásticas apresentam como vantagem a possibilidade de serem produzidas na própria indústria, menor custo, garantem vida-de-prateleira de aproximadamente 3 meses, além de serem leves e inquebráveis (ANJOS, 2006).

O PEN apresenta boa barreira aos gases, resistência mecânica, barreira à radiação UV e resistência térmica na temperatura de pasteurização, mas seu custo é elevado. A empresa AnhauserBusch, detentora da marca Budweiser, chegou a lançar o produto no mercado americano em garrafas de PEN, entretanto o custo de produção das garrafas inviabilizou o processo. A solução nesse caso seria a utilização de PET/PEN para obtenção de custo de embalagem viável (OLIVEIRA, 1999). A combinação de nylon com PET foi demonstrada na Faculdade de Engenharia de Alimentos da Universidade de Campinas (Unicamp), visando aumentar a resistência térmica da garrafa para ser submetida ao processo de pasteurização e a passagem de $\mathrm{CO}_{2}$ e $\mathrm{O}_{2}$. A garrafa foi redesenhada várias vezes até se obter composição e geometria adequada para passá-la em túnel de pasteurização comum, utilizado para garrafas de vidro e latas (LIMA, 2006).

\section{EMBALAGENS FLEXÍVEIS ESTERILIZÁVEIS}

O uso de embalagens flexíveis (pouchs) para a esterilização de alimentosconstitui desafio, pois a mesma não apresenta resistência mecânica para suportar as diferenças de pressão existentes no processo de esterilização. Assim, exigem alterações no desenho dos equipamentos de esterilização que devem apresentar sistema de contrapressão. Isso permite ao processador controlar a pressão independentemente da temperatura, possibilitando o uso de pressões maiores do que as utilizadas com vapor para manutenção da geometria das embalagens (BOWN, 2003).

Para a constituição das bolsas são utilizados materiais plásticos e, por isso, a resistência térmica do pouch é limitada, mas sempre superior a $150^{\circ} \mathrm{C}$ (SARANTÓPOULOS e JESUS Jr, 2005). Os plásticos empregados na formação de filmes autoclaváveis são coextrusados ou laminados de vários polímeros, incluindo PP, poliamida orientada (OPA), PET e PE. Esses coextrusados ou laminados apresentam boa barreira ao oxigênio e à umidade e contam com sistemas de abertura interessantes (BOWN, 2003). Além da resistência térmica, os pouchs precisam ser inertes quimicamente, demonstrar resistência mecânica (especialmente à perfuração) e excelentes propriedades de termossoldagem, constituir boa barreira ao oxigênio, ao vapor d'água e à luz e apresentar boa qualidade de impressão (SARANTÓPOULOS e JESUS Jr, 2005).

Exemplos de estruturas possíveis de camadas dos laminados utilizados na produção de pouchs são: PET/AI/PP; PET/AI/PET/PP; PET/AI/OPA/PP; PET/OPA/Al/PP. Nessas aplicações, os atributos relevantes do filme de $\mathrm{PET}$ são a estabilidade térmica, a excelente resistência à tração e perfuração $\mathrm{e}$ a alta resistência ao impacto e ao início do rasgo. O alumínio (7 a $25 \mu \mathrm{m}$ ) é responsável pela barreira aos gases, aromas, umidade e à luz e também pela resistência estrutural em altas temperaturas. A 
camada interna de polipropileno confere alta resistência à selagem durante o tratamento térmico, resistência térmica, rigidez ("corpo") e inércia química. A poliamida, assim como a camada adicional de PET aumentam a resistência mecânica e garantem a segurança do produto (SARANTÓPOULOS e JESUS Jr, 2005).

As embalagens transparentes são obtidas pela substituição do alumínio por uma camada de plástico que apresente boa barreira aos gases, minimizando a ocorrência da degradação do produto embalado pelo efeito do oxigênio. Nesses casos são utilizados filmes de poliamida orientada, PET revestido com óxidos de silício ou de alumínio ou com poliácido acrílico modificado. Entretanto, mesmo com a utilização desses revestimentos, a vida útil do produto embalado em pouch transparente será menor do que a esperada para o pouch que contenha o alumínio (SARANTÓPOULOS e JESUS Jr, 2005).

A utilização de pouchs é possível pela processo form-fill-seal ou somente fill-seal. No processo de form-fill-seal, o material de embalagem entra em forma de bobina sendo primeiramente termoformado (bolsas ou bandejas) e depois enchido e selado. No processo de fill-seal são usadas embalagens prémontadas, devendo ser apenas enchidas e seladas. A comparação dos dois processos indica maior segurança ao fill-seal, pois há maior tempo entre a formação da embalagem e o seu processamento, o que é importante para a boa solidificação das soldas. A comparação do processo com pouchs e o com latas mostra desvantagem na produção de pouchs, pois o enchimento e a selagem de pouchs é cerca de 3 vezes mais lento que o com latas (SARANTÓPOULOS e JESUS Jr, 2005).

Um dos pontos mais críticos para o processamento de pouch envolve sua selagem (parte mais sensível da bolsa), a primeira a se romper quando há diferença de pressão (SARANTÓPOULOS e JESUS Jr, 2005). É preciso que entre os processos de selagem e autoclavagem exista tempo suficiente para completa solidificação do material da embalagem fundido na selagem, minimizando o risco de abertura da bolsa durante o processo (BOWN, 2003). Após a selagem, os pouchs são colocados em prateleiras perfuradas dentro da autoclave, que garantem a homogeneidade da distribuição de calor e também atuam como barreira física para minimizar sua expansão durante o processo (SARANTÓPOULOS e JESUS Jr, 2005). As autoclaves podem ser estacionárias ou rotativas, sendo as rotativas mais eficientes (SARANTÓPOULOS e JESUS Jr, 2005). A operação de ciclos sincronizados de processos em várias autoclaves permite que o processo seja "semi-continuo" (BOWN, 2003).

O processo de autoclavagem deve ser avaliado com cuidado, considerando-se as variáveis de tempo, temperatura, pressão e contrapressão aplicadas de forma a evitar a perda de integridade da selagem da embalagem, minimizando a entrada de água e a contaminação do produto (BOWN, 2003). A contrapressão evita a delaminação de embalagens laminadas na qual um dos materiais atinge seu limite elástico durante a esterilização, o que poderia gerar deformação permanente e também mantém o volume da embalagem durante todo o processo (SARANTÓPOULOS e JESUS Jr, 2005). O início do resfriamento constitui a fase mais crítica, pois a grande diferença de pressão existente no ambiente interno e externo da embalagem tende a afetar sua estrutura (BOWN, 2003).

A principal vantagem das embalagens flexíveis ou semi-rígidas consiste em menor volume por área de contato com o vapor e também a espessura de parede fina, o que exige menor binômio tempo/ temperatura para se obter determinada letalidade, conservando melhor as características do produto. O espaço vazio pode representar problema ao atuar como isolante, quando a bolsa é colocada na horizontal durante o processo de autoclavagem. Para minimizar esse efeito coloca-se tampa na embalagem, visando conter o ar, havendo pequena área de contato com o produto (BOWN, 2003).

Além da vantagem com relação ao tempo de processo, os pouchs são mais baratos, mais leves, apresentam fácil abertura, ocupam menores volumes e, consequentemente, menor espaço de armazenamento (SARANTÓPOULOS e JESUS Jr, 2005).

Muitas modificações na composição de camadas, número de camadas e forma de obtenção dos laminados (usos de adesivos) foram patenteadas. Os principais objetivos dessas modificações foram a redução de espessura/custo de material, aumento da aderência dos pouchs, melhora das propriedades de barreira e aumento da velocidade de produção das bolsas. Já em 1982, o grupo Shell 
Oil Company patenteou alteração no método de obtenção do laminado mediante processo de extrusãorecobrimento do filme metálico pela camada de plástico de selagem. Isso representou aumento da velocidade do processo de produção das bolsas. A SONOCO DEVELOPMENT INC (US 0110656 A1, 2002) patenteou a substituição da camada de alumínio por uma de poliéster metalizada, visando a redução de custos e de corrosão do metal. A mesma empresa detém outra patente (US 6.842.532B1, 2005), que envolve a utilização de camadas de PET, nylon e PP para a obtenção de pouch transparente com maior resistência térmica e boa qualidade de soldagem. Já a patente da POLYKRAPOV e RAMALINGAM (US 0116910 A1, 2007) inclui camada para impressão de textos e imagens entre as camadas de laminados, melhorando o aspecto visual da embalagem final.

A empresa Tetra Pak® colocou no mercado nova opção de embalagem cartonada para produtos autoclavados dentro da embalagem, denominada Tetra Recart (TETRA PAK, 2004). Essa embalagem se assemelha às tradicionais da empresa elaboradas com 65\% de papel, mas com o diferencial de suportar o processo de esterilização sem alterar suas características, mesmo após $3 \mathrm{~h}$ em ambiente com $100 \%$ de umidade, pressão e temperatura de $130^{\circ} \mathrm{C}$ (TOMOORI, 2005). Suas principais vantagens envolvem o baixo peso, o formato retangular que permite melhor aproveitamento de espaço em estoques e caminhões, a segurança da embalagem para uso doméstico, sem riscos de cortes para os usuários e a qualidade de impressão da rotulagem (TETRA PAK, 2004). Após 10 anos de pesquisa, essa embalagem chegou ao mercado norte americano em 2004 e ao brasileiro em 2006.

Segundo a TETRA LAVAL HOLDINGS \& FINANCES S.A. (US 7.195.803B2, 2007), os principais desafios da embalagem cartonada autoclavável residia na combinação de materiais laminados que não delaminassem durante o processo térmico, garantido sua integridade, sem perda das propriedades de barreira ou alteração na sua conformação. O material de embalagem proposto contém uma camada central de cartão, recoberta dos dois lados com material impermeável a líquidos e barreira a gás entre a camada central e o recobrimento externo, além de agente de selagem com temperatura de fusão superior a $130^{\circ} \mathrm{C}$. Os autores da patente constataram a possibilidade de usar como impermeabilizante externo plásticos como PP, PE e PET, ou blends desses componentes com gramatura de $25-45 \mathrm{~g} / \mathrm{m}^{2}$. Já para a impermeabilização interna empregaram copolímeros de PP ou PE que tolerassem altas umidades durante a estocagem, devendo ser utilizada gramatura de $25-35 \mathrm{~g} / \mathrm{m}^{2}$. Testaram alumínio e polímeros de EVOH tratados com óxido de sílica, mas preferiram o alumínio como barreira a gás e também por auxiliar na termosselagem devido sua alta capacidade de condução de calor. Foi observado também que o selante deveria ter ponto de fusão superior à temperatura do processo e que o PP seria boa opção com gramatura de $20-25 \mathrm{~g} / \mathrm{m}^{2}$.

\section{EFEITO SOBRE A VIDA ÚTIL DE ALIMENTOS}

A embalagem para alimentos tratados termicamente deve, além de não apresentar problemas para envase e processamento nas condições desejadas, atender a outros requisitos que são importantes para a conservação do produto durante a sua vida útil. Esses requisitos estão ligados às propriedades de barreira contra gases como o oxigênio, vapor de água e compostos voláteis (BRODY, 2000) e, também, com a possível interação entre a embalagem e os alimentos. O tratamento térmico pode ser dimensionado para estender a vida útil de um alimento por alguns dias (comum para produtos pasteurizados e refrigerados, como leite), por meses (produtos esterilizados, como leite) e até por anos (produtos esterilizados, como peixes enlatados). Assim, a escolha da embalagem deve ser compatível com o tempo de armazenamento, considerando-se as propriedades de barreira de cada material e as condições de exposição do alimento durante a estocagem.

A embalagem de vidro é considerada inerte e boa barreira aos gases, porém não apresenta proteção natural para a luz, sendo necessária a adição de filtro de UV ou a pigmentação da garrafa (KAREL e LUND, 2003). Além disso, apesar do vidro ser considerado boa barreira, seu sistema de fechamento necessariamente envolve outros materiais (tampas metálicas ou plásticas) que também 
precisam apresentar características adequadas para essa finalidade (BOARD, STEELE e KELLY, 2001).

As embalagens metálicas constituem boa barreira, mas apresentam a recravação e a solda como pontos críticos, especialmente, com relação à barreira aos gases (KAREL e LUND, 2003). Deve-se considerar também a possível interação alimento-embalagem que pode causar a migração de compostos tóxicos, ou o ataque da embalagem pela ação dos alimentos ácidos (KAREL e LUND, 2003), que podem reduzir significativamente a vida útil do produto embalado.

As embalagens plásticas apresentam propriedades de barreiras inferiores, tanto ao vapor de água como ao oxigênio, que as metálicas ou de vidro, sendo muitas vezes necessário combinar dois ou mais materiais para se obter valores de permeabilidade adequados à conservação de alimentos. As embalagens plásticas também são passíveis de apresentar permeabilidade a outros compostos orgânicos voláteis, como os aromas, que podem ser transferidos tanto do meio externo como do alimento para o meio externo. Em ambos os casos ocorre rápida deterioração do produto, motivo pelo qual a embalagem também deve oferecer barreira para esses compostos (SARANTÓPOULOS, 1998). A luz pode ser outro agravante para a vida útil de alimentos embalados em plástico, sendo necessária a pigmentação das embalagens para minimizar seu efeito (KAREL e LUND, 2003). Outro fator crítico para embalagens plásticas é a migração de compostos para os alimentos (PADULA, 1997).

A vida útil dos alimentos não é determinada apenas pelo desenvolvimento de microrganismos em nível inaceitável, mas também pela degradação físico-química por fatores como oxigênio e luz. A embalagem deve ser adequada para o processamento desejado, apresentar boas propriedades de barreiras que garantam sua vida útil permitindo que haja tempo para a distribuição e consumo do alimento. Entretanto, é necessário considerar que o aumento das propriedades de barreira eleva o custo da embalagem final e, por isso, essas propriedades devem ser corretamente dimensionadas, balanceando-se custo, vida útil, segurança, praticidade e tendências de mercado.

\section{CONCLUSÃO}

Existem várias opções para o envase de alimentos termicamente tratados, desde as tradicionais embalagens de vidro e latas até as inovadoras embalagens plásticas. No mercado, cada vez mais competitivo, a busca por redução de custo promoveu alterações no perfil das embalagens tradicionais e nas desenvolvidas recentemente.

Para as embalagens tradicionais, a busca pela diminuição de custo de fabricação foi obtida pela redução da quantidade de material utilizado nas embalagens mediante métodos de produção mais modernos e geometrias mais adequadas. Também ocorreu o desenvolvimento de novos métodos de fechamento, mais fáceis e mais seguros para os consumidores, e a obtenção de formatos de embalagem mais arrojados para a diferenciação dos produtos no mercado.

As embalagens plásticas passaram por alterações estruturais, de geometria e composição para permitir sua aplicação em alimentos termicamente tratados na embalagem e, também, o enchimento a quente. A alavancagem desses materiais de embalagem com relação às tradicionais latas e vidros deve-se comumente ao menor custo das matérias-primas, facilidade da produção, espaço de estocagem e transporte. O grande número de pesquisas realizadas resultou em várias opções para utilização de recipientes plásticos para o enchimento a quente e também embalagens flexíveis autoclaváveis. Outra inovação para embalagem de alimentos termicamente processados é a utilização de embalagens cartonadas para esterilização do produto, que suportam altas pressões, temperatura e umidade.

Considerando-se a variedade de embalagens disponíveis no mercado pode-se concluir que os produtores de alimentos contam com diversas opções para envase e diferenciação dos seus produtos. A escolha da embalagem sempre deverá ser baseada nas necessidades do produto (tipo de processo) 
e também das barreiras necessárias para sua preservação pós-processamento (como umidade e gases), tomando por base a vida útil desejada e o custo final requerido para tornar o produto competitivo no mercado.

\section{ABSTRACT}

\section{INNOVATIONS IN PACKAGE SYSTEMS FOR HEAT PROCESSED FOOD}

This literature review aimed to evaluate the different package systems available to heat processed food and how they may affect the kind of process used and the final quality of the products. Were approached the main heat processes and their requirements concerning thermal and mechanical resistance of the package, as well as the advantages and limitations of the main used materials. It were also described the recent developments in order to minimize the restrictions of each type of material, improving its resistance and reducing costs, beyond barrier proprieties required to prevent undesirable physical-chemical changes in food during its storage caused by humidity, oxidation and material migration from package. It was concluded that there are many package options to heat treated food and that while traditional packages are being studied for weight reduction in order to be competitive, flexible or plastic packages are being formulated to be compatible to heat processing at low cost.

KEY-WORDS: HEAT TREATMENT; HOT FILL; HEAT RESISTANCE OF PLASTIC PACKAGE.

\section{REFERÊNCIAS}

1 ANJOS, C.A.R. Embalagens de poli(etileno tereftalato) PET para bebidas alcoólicas - uma realidade. Revista Engarrafador Moderno, v. 142, p. 26 - 34, 2006.

2 ANSARI, M.D.I.A.; DATTA, A.K. An overview of sterilization methods for packaging materials used in aseptic packaging systems. Food and Bioproducts Processing, v.81, n.1, p. 57-65, 2003.

3 AVERY, S.M.; HUDSON, J.A.; PHILLIPS, D.M. Use of response surface models to predict bacterial growth from time/ temperature histories. Food Control, v. 7, n. 3, p. 121-128, 1996.

4 ÁVILA, I.M.L.B.; SILVA. C.L.M. Methodologies to optimize thermal processing conditions: an overview. In: OLIVEIRA, F.A.R.; OLIVEIRA, J.C. Processing foods: quality optimization and process assessment. London: CRC Press, 1999. Chap. 4

5 BOARD, P.W. Canned foods - an outline of the basic science and technology. In: MOIR,C.J.; ANDREW-KABILAFKAS, C.; ARNOLD, G.; COX, B.M.; HOCKING, A.D.; JENSON, I. Spoilage of processed foods: causes and diagnosis. Marrickville: Southwood Press, 2001. Capítulo 2.2.

6 BOARD, P.W.; STEELE, R.J.; KELLY, M. The role of packaging in food preservation. In: MOIR,C.J.; ANDREW-KABILAFKAS, C.; ARNOLD, G.; COX, B.M.; HOCKING, A.D.; JENSON, I. Spoilage of processed foods: causes and diagnosis. Marrickville: Southwood Press, 2001. Chap. 2.8.

7 BOWN, G. Developments in conventional heat treatment. In: ZEUTHEN, P.; BOGH-SORENSEN, L. Food preservation techniques. Cambrigde: Woodhead Publishing, 2003. Chap. 9.

8 BRODY, A.L. Developments of packaging for food products. In: BRODY, A.L.; LORD, J.B. Developing new food products for a changing marketplace. Boca Raton: CRC Press, 2000. Chap. 8.

9 CHIPLEY, J.R. Sodium benzoate and benzoic acid. In: DAVIDSON, P.M.; SOFOS, J.; BRANEN, A.L. Antimicrobials in food. $3^{\text {rd }}$ ed. Boca Raton: CRC Press. 2005. Chap. 2.

10 CUTTER, C.N. Microbial control by packaging: a review. Critical Reviews in Food Science and Nutrition, v.42, n.2, p. 151-161, 2002.

11 CHUTINTRASRI, B.; NOOMHORM, A. Color degradation kinetics of pineapple puree during thermal processing. LWT, v. 40, p. 300-306, 2007.

12 DAMASCENO, L.F.; FERNANDES, F.A.N.; MAGALHÃES, M.M.A.; BRITO, E.S. Non-enzymatic browning in clarified cashew apple juice during thermal treatment: kinetics and process control. Food Chemistry, v. 106, p. 172-179, 2008.

13 DANTAS, F.B.H.; JAIME, S.B.M. Redução de peso em embalagem de vidro. Informativo CETEA: Boletim de Tecnologia e Desenvolvimento de Embalagens, v. 15, n.3, p.3-5, 2003. 
14 EASTMAN KODAK COMPANY. SHEPHERD, F.A.; LIGHT, R.R. Tricomponent polymerer blends of poly(ethylene terepthalate), poly(ethylene naphthalate) and a copoliester. US 5.006.613. 09/04/1991.

15 FELLOWS, P.J. Food processing technology: principles and practice $2^{\text {nd }}$ ed. Cambridge: Woodhead Publishing, 2000. Chap. 11.

16 GARCIA, E. A evolução da família dos polietilenos. Informativo CETEA: Boletim de Tecnologia e Desenvolvimento de Embalagens, v. 14, n.1, p.5-7, 2002.

17 GHANI, A.A.G.; FARID, M.M.; CHEN, X.D.; RICHARDS, P. Numerical simulation of natural convection heating of canned food by computational fluid dynamics. Journal of Food Engineering, v.41, p.55-64, 1999.

18 GHANI, A.A.G.; FARID, M.M.; CHEN, X.D.; RICHARDS, P. Thermal sterilization of canned food in a 3-D pouch using computational fluid dynamics. Journal of Food Engineering, v.48, p.147-56, 2001.

19 GILES, G.A.; BAIN, D.R. Technology of plastics packaging for the consumer market. Sheffield: Sheffield Academic Press, 2001.

20 GONZALEZ, P.M.; ZEPKA, M.M. Embalagens metálicas. Portal da Embalagem. Fundação Universidade Federal do Rio Grande. Disponível em: http://www.furg.br/portaldeembalagens/. Acesso em: 08/04/2008.

21 GRAHAM PACKING COMPANY, L.P. PRITCHETT Jr, R.A.; NOLL, A.; BYSICK, S. Multi-sided spiraled plastic container. US 2007/0125743A1. 07/Jun./2007.

22 HARNESS, DICKEY \& PIERCE, P.L.C. LANE, M.T.; WEISSMANN, D.; NIEVIEROWSKI, J.; CASZATT. B. Rectangular hotfilled container. US 2007/0039918A1. 22/Fev./2007.

23 HNA HOLDINGS, INC. CHARBONNEAU, L.F. JOHNSON, R.E. Polyester container and method for making same. US 6.063.465. 16/May/2000.

24 HOCKING, A.D. Aspergillus and related teleomorphs. In: BLACKCURN, C.W. Food spoilage microorganisms. Boston: CRC Press, 2006. Chap. 17.

25 JACXSENS, L.; DEVLIEGHERE, F.; RAGAERT, P.; VANNESTE, E.; DEBEVERE, J. Relation between microbiological quality, metabolite production and sensory quality of equilibrium modified atmosphere packaged fresh-cut produce. International Journal of Food Microbiology, v. 83, p. 263-280, 2003.

26 JAIME, S.B.M.; ORTIZ, S.A. Embalagens de vidro: inovações x competitividade. Informativo CETEA: Boletim de Tecnologia e Desenvolvimento de Embalagens, v. 13, n.1, p.9-11, 2001.

27 JAIME, S.B.M. Novas tecnologias para um maior desenvolvimento na área de embalagens de vidro. Informativo CETEA: Boletim de Tecnologia e Desenvolvimento de Embalagens, v. 9, n.4, p.7-8, 1997.

28 KAREL, M.; LUND, D. Protective packaging. In: KAREL, M.; LUND, D. Physical principles of food preservation. $2{ }^{\text {nd }}$ ed. New York: Marcel Dekker, 2003. Chap. 12

29 KANSAI PAINT CO. LTD. TAKAMI, S.; FUKUDOME, K. Ultraviolet-curing coating composition for cans. US 005721020A. 24/Feb./ 1998 .

30 LIMA. R. Pesquisa coloca cerveja na era da embalagem PET. Correio Popular: Cidades, Campinas, p.4, 30 jul. 2006.

31 MAROULIS, Z.; SARAVACOS, G. Thermal processing of foods. In: MAROULIS, Z.; SARAVACOS, G. Food process design. New York: Marcel Dekker, 2003. Chap. 8.

32 MCLELLAN, M.R.; PADILLA-ZAKOUR, O.I. Juice processing. In: BARRETT, D.; SOMOGYI, L.; RAMASWAMY, H. Processing fruits: science and technology. $2^{\text {nd }}$ ed. Boca Raton: CRC Press, 2005. Chap. 4.

33 OLIVEIRA, L.M. O PET no mercado de cerveja. Jornal do Plástico. Niterói, Nov.2009. Disponível em: <http:// www.jorplast.com.br/Jonov99/nov9912.html>. Acesso em: 04 jul. 2008.

34 ORTIZ, S.A. Embalagens de vidro: resistência $x$ tratamentos e revestimentos superficiais. Informativo CETEA: Boletim de Tecnologia e Desenvolvimento de Embalagens, v. 8, n.5, p.2-4, 1996.

35 OWENS-ILLINOIS INC. ESTES, A.E.; STACZEK, D.J. Round juice bottle formed from a flexible material. US 4.610.366. 09/Sep./1986.

36 OWENS-ILLINOIS INC. ZHANG, Q.P.; GRANT, R.P.; ESHBACK, K.J. STAVROPOULOS, N.J. Polygonal hot-fill container, package and method of making. US 2004/0129598 A1. 08/Jul./2004.

37 PADULA, A. O acetaldeído e a água mineral. Informativo do Centro de Tecnologia em Embalagens - CETEA, v. 9 , n. 2, p. 9-10, 1998. 
38 PINHO, C.R.G. Processamento de leite desnatado através da tecnologia de homogeneização a ultra-alta pressão (HUAP). 2007. 176 p. Tese (Doutorado em Tecnologia de Alimentos) - Faculdade de Engenharia de Alimentos, Universidade Estadual de Campinas. Campinas, 2007.

39 PFLUG, I. J. Microbiology and engineering of sterilization processes. $10^{\text {th }}$ ed. Minneapolis: Environmental Sterilization Laboratory, 1999.

40 POLYKRAPOV, A.Y.; RAMALINGAM, B. Multilayer laminated structures. US 0116910 A1, $24 /$ May/2007.

41 POTTER, N.N.; HOTCHIKISS, J.H. Food science. $5^{\text {th }}$ ed. New York: Chapman \& Hall, 1995.608 p.

42 PRIA. M.D. Tendência de embalagens para bebidas. Brasil Alimentos, n.5, p. 24-28, 2000.

43 RICKMAN, J.C.; BARRETT, D.M.; BRUHN,C.M. Review: nutritional comparison of fresh, frozen and canned fruits and vegetables. Part 1. Vitamins $\mathrm{C}$ and $\mathrm{B}$ and phenolic compounds. Journal of the Science of Food and Agriculture, v. 87, p. 930-944, 2007.

44 SANDEEP, K.P.; SIMUNOVIC, J.; SWARTZEL, K.R. Developments in aseptic processing. In: RICHARDSON, P. Improving the thermal processing foods. Abington: Woodhead Publishing, 2004. Chap. 9.

45 SARANTÓPOULOS, C.I.G.L. Retenção, absorção e perdas de aromas em embalagens plásticas. Informativo do Centro de Tecnologia em Embalagens - CETEA, v. 10, n. 3, p. 8-9, 1998.

46 SARANTÓPOULOS, C.I.G.L.; JESUS JR, I.A. Embalagens plásticas esterilizáveis - reinvenção e tendências. Informativo do Centro de Tecnologia em Embalagens - CETEA. 2007. Disponível em <http://www.cetea.ital.org.br/cetea/ informativo/v17n3/v17n3_artigo3.html>. Acesso em: 03/04/2008.

47 SHELL OIL COMPANY. Retort-sterilizable pouch. US 4.359.495, 16/Nov./1982.

48 SHIMODA, M.; KATOH, T.; SUZUKI, J.; KAWARAYA, A.; IGURA, N.; HAYAKAWA, I. Changes in the odors of reconstituted apple juice during thermal processing. Food Research International, v. 36, p. 439-445, 2003

49 SONOCO DEVELOPMENTS INC. BENSUR, F.J. Flexible non-foil-based retort package. US 0110656 A1, $15 /$ Aug./ 2002.

50 SONOCO DEVELOPMENTS INC. BENSUR, F.J. Laminate packing material. US 6.846.532 B1, 25/Jan./2005.

51 STUMBO, C.R. Thermobacteriology in food processing. London: Academic Press, 1973.

52 TEIJIN LIMITED. MURUKAMI, T.; ICHIHASSHI, T.;HASEGAWA, K. Biaxially oriented polyester film. US 005424121A, 03/Jun./1995.

53 TEIJIN LIMITED. HASEGAWA, K..; ASAI,T.; ONO, M.; MURAKAMI, Y. Biaxially oriented laminated polyester film for use as film to be bonded onto metal sheet. US 005618621A, 08/Apr./1997.

54 TETRA LAVAL HOLDINGS \& FINANCES S.A. ANDERSSON, T.; KJELGAARD, T. Packaging laminate for a retortable packing container. US 7.195.803B2, 27/Mar./2007.

55 TETRA PAK. Tetra Recart a única embalalgem cartonada para autoclaves. 2004. Disponível em: <http:// www.tetrapak.com.br/negocios/embalagens/volumes_recart.asp?idFamilia=0>.Acesso em: 09/05/2008.

56 TETRA PAK. História. 2008. Disponível em: < http://www.tetrapak.com.br/sobre/historia/index_historia.asp>. Acesso em: 09/05/2008.

57 TOMOORI,S. The world's first retortable carton: tetra recart. JPI Journal, v.43, n.10, p. 732-736, 2005.

58 TOYO SEIKAN KAISHA, LTD. SATO, K.; IKENAGA, H.; ICHIKAWA, K.; MOROFUJI, A. Resin-coated metal plate, metal can and can cap. US 00676470B2, 20/Jul./2004.

59 TUNG, M.A.; BRITT, I.J.; YADA, S. Packaging considerations. In: ESKIN, N.A.M.; ROBINSON, D.S. Food shelf life stability: chemical, biochemical and microbiological changes. Boca Raton: CRC Press LLC, 2000. Chap. 4.

60 UNION CAMP CORPORATION. BOSE, A.K.; STRATER, K.J. Hot-fill polyethylene bags. US 4.994.324. 19/Fev./1991.

61 VAZQUEZ-CAICEDO, A.L.; SCHILLING, S.; CARLE, R.; NEIDHARD, S. Effect of thermal processing and fruit matrix on $\beta$-carotene stability and enzyme inactivation during transformation of mangos into purée and nectar. Food Chemistry, v.102, p.1172-1186, 2007.

62 VIEIRA, J.D. Termossoldagem. Serviço Brasileiro de Respostas Técnicas. 2007. Disponível em: <http:// sbrtv1.ibict.br/upload/sbrt6711.pdf?PHPSESSID=6aa56910df57f5c60f1bee9de0deeaf0>. Acesso em: 03/04/2008. 
27063 WALKER, M.; PHILLIPS, C.A. The effect of preservatives on alicyclobacillus acidoterrestris and Propionium bacterium cyclohexanicum in fruit juice. Food Control. 2007. Disponível em: <www.elsevier.com/locate/foodcont> Acesso em: 22/04/2008.

64 WANG, J. Design optimization of rigid metal conta/iners. Finite Elements in Analysis and Design, v. 37, p. 273286, 2001. 